Editorial

\title{
Novel Non-Precious Metal Electrocatalysts for Oxygen Electrode Reactions
}

\author{
Nicolas Alonso-Vante ${ }^{1, *} \mathbb{C}$, Yongjun Feng ${ }^{2}$ and Hui Yang ${ }^{3}$ \\ IC2MP-UMR CNRS 7285, University of Poitiers, 86022 Poitiers, France \\ 2 State Key Laboratory of Chemical Resource Engineering, College of Chemistry, Beijing University of \\ Chemical Technology (BUCT), No. 15, Beisanhuan East Road, Chaoyang District, Beijing 100029, China \\ 3 Shanghai Advanced Research Institute, Chinese Academy of Sciences, No. 99, Haike Road, \\ Shanghai 201210, China \\ * Correspondence: nicolas.alonso.vante@univ-poitiers.fr
}

Received: 16 August 2019; Accepted: 26 August 2019; Published: 29 August 2019

The collection of articles in the Catalyst special issue entitled "Novel Non-Precious Metal Electrocatalysts for Oxygen Electrode Reactions" mirrors the relevance and strengths to address the inevitable increasing demand of energy. This subject matter has stimulated considerable research on alternative energy harvesting technologies, conversion, and storage systems with high efficiency, cost-effective, and environmentally friendly systems, such as fuel cells, rechargeable metal-air batteries, unitized regenerative cells, and water electrolyzers [1-5]. In these devices, the conversion between oxygen and water plays a key step in the development of oxygen electrodes: oxygen reduction reaction (ORR), and oxygen evolution reaction (OER). To date, the state-of-art catalysts for ORR consist of platinum-based materials $(\mathrm{Pt})$, while ruthenium $(\mathrm{Ru})$ - and iridium (Ir)-oxides are the best known OER catalyst materials. The scarcity of the precious metals, their prohibitive cost, and declining activity greatly hamper the practice for large-scale applications. It is thus of paramount practical importance and interest to develop efficient and stable materials for the oxygen electrode based on earth-abundant non-noble metals [6-8]. In this connection, novel non-precious metal electrocatalysts for oxygen electrode reactions have been explored based on the innovative design in chemical compositions, structure, morphology, and supports.

This Special Issue covers recent progress and advances in novel non-precious metal electrocatalysts tailoring with high activity and stability for the catalytic conversion between water and oxygen. Additionally, electrocatalytic activity, selectivity, durability, and the mechanism for single or bifunctional oxygen electrodes, a current key topic in electrocatalysis, is an important subject for this Special Issue.

This special issue comprises a total of 10 scientific articles of which three are review articles and seven are research articles from respected colleagues around the world. Herein, one review paper and five research articles pay special attention to ORR high-performance electrocatalysts. For example, Xiong et al. [9] summed up recent progress on three-dimensional hetero-atom-doped nanocarbon for metal-free ORR electrocatalysis; Schardt et al. [10] carefully investigated the influence of the structure-forming agent on the composition, morphology and ORR performance of Fe-N-C electrocatalysts; Zhu et al. [11] developed a novel metal-organic framework route to embed Co nanoparticles into multi-walled carbon nanotubes for ORR in alkaline media; Liu et al. [12] fabricated $\mathrm{N}, \mathrm{S}$ co-doped carbon nanofibers derived from bacterial cellulose/poly(methylene blue) hybrid for ORR; Liu et al. [13] prepared porous Fe-N-S/C electrocatalysts for ORR in a Zn-air battery using g- $\mathrm{C}_{3} \mathrm{~N}_{4}$ and 2,4,6-tri(2-pyridyl)-1,3,5-triazine as binary nitrogen precursors; Zeng et al. [14] reported the $\mathrm{Ag}_{4} \mathrm{Bi}_{2} \mathrm{O}_{5} / \mathrm{MnO}_{2}$ corn/cob-like nanomaterial as a superior catalyst for ORR in alkaline media. One review paper and one research article are involved in the OER electrocatalysts. For instance, $\mathrm{Li}$ et al. [15] summarized recent advances and perspectives on host-guest engineering of layered double 
hydroxides (LDH) to manufacture high-performance OER electrocatalysts; Liu et al. [16] engineered mesoporous $\mathrm{NiO}$ electrocatalyst with enriched electrophilic $\mathrm{Ni}^{3+}$ and $\mathrm{O}$ for high-performance OER. Likewise, one review and one research paper are concern bifunctional electrocatalysts. For example, Zhong et al. [17] reviewed recent advance on the design, synthesis and electrocatalytic performance of cobalt-based electrocatalysts for oxygen electrode reactions and hydrogen evolution reaction; and Qiao et al. [18] designed and synthesized cobalt and nitrogen co-doped graphene-carbon nanotube aerogel as an efficient bifunctional electrocatalysts towards ORR and OER.

Summing-up, this special issue covers recent progress on high-performance and non-precious oxygen electrode catalysts providing novel ideas to tailor potential electrocatalytic materials. The Guest Editors really hope that the readers will appreciate the variety of contributions neighboring their own field of research.

Funding: This research received no external funding.

Conflicts of Interest: The authors declare no conflict of interest.

\section{References}

1. Dekel, D.R. Review of cell performance in anion exchange membrane fuel cells. J. Power Sour. 2018, 375, 158-169. [CrossRef]

2. Tahir, M.; Pan, L.; Idrees, F.; Zhang, X.W.; Wang, L.; Zou, J.J.; Wang, Z.L. Electrocatalytic oxygen evolution reaction for energy conversion and storage: A comprehensive review. Nano Energy 2017, 37, 136-157. [CrossRef]

3. Ghosh, S.; Basu, R.N. Multifunctional nanostructured electrocatalysts for energy conversion and storage: Current status and perspectives. Nanoscale 2018, 10, 11241-11280. [CrossRef]

4. Omrani, R.; Shabani, B. Review of gas diffusion layer for proton exchange membrane-based technologies with a focus on unitised regenerative fuel cells. Int. J. Hydrog. Energy 2019, 44, 3834-3860. [CrossRef]

5. Xu, H.M.; Ci, S.Q.; Ding, Y.C.; Wang, G.X.; Wen, Z.H. Recent advances in precious metal-free bifunctional catalysts for electrochemical conversion systems. J. Mater. Chem. A 2019, 7, 8006-8029. [CrossRef]

6. Liu, D.D.; Tao, L.; Yan, D.F.; Zou, Y.Q.; Wang, S.Y. Recent advances on non-precious metal porous carbon-based electrocatalysts for oxygen reduction reaction. ChemElectroChem 2018, 5, 1775-1785. [CrossRef]

7. Zhu, Y.P.; Guo, C.X.; Zheng, Y.; Qiao, S.Z. Surface and interface engineering of noble-metal-free electrocatalysts for efficient energy conversion processes. Acc. Chem. Res. 2017, 50, 915-923. [CrossRef]

8. Wu, G.; More, K.L.; Johnston, C.M.; Zelenay, P. High-performance electrocatalysts for oxygen reduction derived from polyaniline, iron, and cobalt. Science 2011, 332, 443-447. [CrossRef]

9. Xiong, D.; Li, X.; Fan, L.; Bai, Z. Three-dimensional heteroatom-doped nanocarbon for metal-free oxygen reduction electrocatalysis: A review. Catalysts 2018, 8, 301. [CrossRef]

10. Schardt, S.; Weidler, N.; Wallace, W.; Martinaiou, I.; Stark, R.; Kramm, U. Influence of the structure-forming agent on the performance of Fe-N-C Catalysts. Catalysts 2018, 8, 260. [CrossRef]

11. Zhu, H.; Li, K.; Chen, M.; Cao, H.; Wang, F. A novel metal-organic framework route to embed Co nanoparticles into multi-walled carbon nanotubes for effective oxygen reduction in alkaline media. Catalysts 2017, 7, 364. [CrossRef]

12. Liu, J.; Ji, Y.-G.; Qiao, B.; Zhao, F.; Gao, H.; Chen, P.; An, Z.; Chen, X.; Chen, Y. N,S Co-doped carbon nanofibers derived from bacterial cellulose/poly(methylene blue) hybrids: Efficient electrocatalyst for oxygen reduction reaction. Catalysts 2018, 8, 269. [CrossRef]

13. Liu, X.; Chen, C.; Cheng, Q.; Zou, L.; Zou, Z.; Yang, H. Binary nitrogen precursor-derived porous Fe-N-S/C catalyst for efficient oxygen reduction reaction in a $\mathrm{Zn}$-air battery. Catalysts 2018, 8, 158. [CrossRef]

14. Zeng, X.; Pan, J.; Sun, Y. Preparation of $\mathrm{Ag}_{4} \mathrm{Bi}_{2} \mathrm{O}_{5} / \mathrm{MnO}_{2}$ corn/cob like nano material as a superior catalyst for oxygen reduction reaction in alkaline solution. Catalysts 2017, 7, 379. [CrossRef]

15. Li, J.; Jiang, S.; Shao, M.; Wei, M. Host-guest engineering of layered double hydroxides towards efficient oxygen evolution reaction: Recent advances and perspectives. Catalysts 2018, 8, 214. [CrossRef]

16. Liu, X.; Zhai, Z.-Y.; Chen, Z.; Zhang, L.-Z.; Zhao, X.-F.; Si, F.-Z.; Li, J.-H. Engineering mesoporous $\mathrm{NiO}$ with enriched electrophilic $\mathrm{Ni}^{3+}$ and $\mathrm{O}-$ toward efficient oxygen evolution. Catalysts 2018, 8, 310. [CrossRef] 
17. Zhong, H.; Campos-Roldán, C.; Zhao, Y.; Zhang, S.; Feng, Y.; Alonso-Vante, N. Recent advances of cobalt-based electrocatalysts for oxygen electrode reactions and hydrogen evolution reaction. Catalysts 2018, 8, 559. [CrossRef]

18. Qiao, X.; Jin, J.; Fan, H.; Cui, L.; Ji, S.; Li, Y.; Liao, S. Cobalt and nitrogen Co-doped graphene-carbon nanotube aerogel as an efficient bifunctional electrocatalyst for oxygen reduction and evolution reactions. Catalysts 2018, 8, 275. [CrossRef] 